\title{
Comparing the IHME COVID-19 health service utilization forecasting team's predicted cumulative COVID-19 deaths to actual deaths
}

\author{
Jinkinson Smith ${ }^{1}$ \\ ${ }^{1}$ PREreview
}

August 6, 2020

\begin{abstract}
On March 30, 2020, the COVID-19 health service utilization forecasting team at the University of Washington's Institute for Health Metrics and Evaluation (IHME) published national and state-level projections of the number of COVID-19 deaths in the United States anticipated in the next four months (i.e. by July 30, 2020). At the time of writing (May 5, 2020), less than half of the time between that paper's publication and the date to which its predictions apply has passed, but comparing these predictions to the actual number of deaths reported so far is still useful in determining whether the models have significantly underestimated the number of deaths. Data regarding the cumulative number of predicted COVID-19 deaths per state was obtained from the IHME's published paper on medRxiv, as were the corresponding lower and upper bounds accompanying each state-level prediction. These predictions covered all 50 states and the District of Columbia. They were then compared to the reported total number of deaths based on data from the COVID Tracker (as of May 5, 2020). The findings indicate that most of the included regions still have not surpassed the number of COVID-19 deaths predicted that they would experience cumulatively, though seven states (Connecticut, New Jersey, New York, Massachusetts, Maryland, Rhode Island, and Illinois) and the District of Columbia have already done so. Nationally, the total number of deaths reported in the United States as of May 5, 2020 is 62,698 , which represents about $77 \%$ of the 81,111 deaths predicted in the United States by July 30 , 2020. The total national number of deaths has increased at a rate of about 1,726 deaths per day since the IHME report was published. If this trend continues at the same rate until July 30, the number of Americans who would have died from COVID-19 at that point would be 213,689 , more than twice the IHME prediction.
\end{abstract}

\section{Introduction}

Numerous mathematical models have been developed to project the ongoing COVID-19 pandemic in the United States (e.g. (Best, 2020)). The aim of this paper is to evaluate the accuracy of the predicted numbers of cumulative deaths made by the COVID-19 health service utilization forecasting team at the University of Washington's Institute for Health Metrics and Evaluation (IHME) in a non-peer-reviewed paper published on March 30, 2020 on the preprint server medRxiv. These predictions included the predicted number of deaths over the following four months for the United States as a whole, as well as for each of the 50 states and the District of Columbia. (and Christopher JL Murray, 2020) My ability to assess these predictions' accuracy is limited by the fact that, whereas the predictions were intended to reflect all deaths over the next four months (which I take to mean by July 30, 2020), only slightly more than one month has passed since their paper was published at the time of writing. Thus, even if the IHME's predictions were all perfectly accurate, you would expect the number of deaths in the United States and each region therein to be, at the time of writing, significantly less than the corresponding predicted number of deaths. However, if the 
number of deaths has already, by May 5, matched or even exceeded the number predicted to occur by July 30 , this would provide clear evidence that the predicted numbers of death were significantly too low.

\section{Methods}

I obtained the number of deaths predicted by the IHME over the four months (i.e. from March 30-July 30, 2020) for each state, as well as the corresponding predicted lower and upper bounds, from the aforementioned medRxiv paper((and Christopher JL Murray, 2020), Table 1). I obtained the actual number of deaths in the United States for each state from the COVID Tracking Project's spreadsheet on May 5, 2020 at 4:18 PM.(Coronavirus numbers by state, n.d.) The time at which each state's data was last updated in that spreadsheet varied from state to state and is shown in table 1 below. As this table shows, each state's data was last updated between May 2 and May 4, 2020, inclusive. Nevertheless, for consistency, I will be referring to the number of actual deaths based on these data as being "as of May 5, 2020".

\begin{tabular}{|c|c|c|}
\hline State & Last update (ET) & Check time (ET \\
\hline AK & 05/04 0:00 & 05/04 15:27 \\
\hline AL & 05/04 0:00 & 05/04 16:24 \\
\hline AR & 05/03 15:40 & 05/04 16:07 \\
\hline AS & 05/03 0:00 & 05/04 15:35 \\
\hline $\mathrm{AZ}$ & 05/04 0:00 & 05/04 15:35 \\
\hline CA & 05/04 14:00 & 05/04 16:38 \\
\hline $\mathrm{CO}$ & 05/03 18:00 & 05/04 15:17 \\
\hline $\mathrm{CT}$ & 05/03 16:00 & 05/04 16:35 \\
\hline $\mathrm{DC}$ & 05/03 0:00 & 05/04 16:14 \\
\hline $\mathrm{DE}$ & 05/03 18:00 & 05/04 16:28 \\
\hline FL & 05/04 9:12 & 05/04 15:25 \\
\hline GA & 05/04 15:25 & 05/04 16:37 \\
\hline GU & 05/04 7:40 & 05/04 15:36 \\
\hline HI & 05/03 18:00 & 05/04 15:48 \\
\hline IA & 05/03 12:00 & 05/04 14:51 \\
\hline ID & 05/02 19:00 & 05/04 15:27 \\
\hline IL & 05/04 0:00 & 05/04 16:08 \\
\hline IN & 05/03 23:59 & 05/04 15:20 \\
\hline $\mathrm{KS}$ & 05/03 10:00 & 05/04 14:55 \\
\hline $\mathrm{KY}$ & 05/03 17:00 & 05/04 15:56 \\
\hline LA & 05/04 13:00 & 05/04 16:28 \\
\hline MA & 05/04 12:00 & 05/04 16:30 \\
\hline MD & 05/04 10:00 & 05/04 15:12 \\
\hline $\mathrm{ME}$ & 05/03 11:59 & 05/04 15:09 \\
\hline MI & 05/03 11:00 & 05/04 16:35 \\
\hline $\mathrm{MN}$ & 05/04 0:00 & 05/04 14:58 \\
\hline $\mathrm{MO}$ & 05/04 15:00 & 05/04 15:39 \\
\hline MP & 05/04 0:00 & 05/04 15:14 \\
\hline MS & 05/03 19:00 & 05/04 15:58 \\
\hline MT & 05/04 0:00 & 05/04 14:39 \\
\hline $\mathrm{NC}$ & 05/04 10:50 & 05/04 16:31 \\
\hline ND & 05/04 13:00 & 05/04 14:36 \\
\hline NE & 05/03 20:45 & 05/04 14:35 \\
\hline $\mathrm{NH}$ & 05/03 9:00 & 05/04 16:38 \\
\hline NJ & 05/04 13:00 & 05/04 14:45 \\
\hline
\end{tabular}




\begin{tabular}{|c|c|c|}
\hline NM & 05/03 17:58 & 05/04 16:13 \\
\hline NV & 05/04 11:00 & 05/04 16:33 \\
\hline NY & 05/04 0:00 & 05/04 16:32 \\
\hline $\mathrm{OH}$ & 05/04 14:00 & 05/04 14:19 \\
\hline OK & 05/03 0:00 & 05/04 14:11 \\
\hline OR & 05/04 11:00 & 05/04 16:35 \\
\hline PA & 05/04 0:00 & 05/04 15:21 \\
\hline PR & 05/04 6:00 & 05/04 15:32 \\
\hline RI & 05/04 0:00 & 05/04 15:24 \\
\hline $\mathrm{SC}$ & 05/03 15:30 & 05/04 14:43 \\
\hline SD & 05/03 18:00 & 05/04 15:35 \\
\hline $\mathrm{TN}$ & 05/04 15:00 & 05/04 16:01 \\
\hline $\mathrm{TX}$ & 05/04 13:15 & 05/04 15:34 \\
\hline UT & 05/03 15:00 & 05/04 15:38 \\
\hline VA & 05/03 17:00 & 05/04 14:55 \\
\hline VI & 05/03 20:30 & 05/04 14:57 \\
\hline VT & 05/04 10:20 & 05/04 16:40 \\
\hline WA & 05/03 2:59 & 05/04 16:19 \\
\hline WI & 05/04 0:00 & 05/04 15:56 \\
\hline WV & 05/04 10:00 & 05/04 16:17 \\
\hline & 05/04 1:56 & 05/04 16:0 \\
\hline
\end{tabular}


aTable 1. The update and check times by state for the data on actual COVID-19 deaths I obtained from the COVID-19 Tracking Project's website. If you go to this link https://covidtracking.com/data/ and click "as a spreadsheet" in the text near the top of the page, it will take you to this same spreadsheet (tab "States Current").

I did not include data from Puerto Rico, the Virgin Islands, Guam, or the Northern Mariana Islands in the 
current study. This is because while data for these regions was included in the COVID Tracking Project's spreadsheet, it was not included in the IHME predictions, which as mentioned before included only the 50 U.S. states and the District of Columbia (hereafter simply "the United States".

\section{Results}

The total number of reported COVID-19 deaths in the United States as of May 5, 2020 was 62,698. Table 2 below shows the total number of deaths reported by each state and the District of Columbia in the United States.

\begin{tabular}{ll}
\hline State & Deaths \\
AK & 9 \\
AL & 296 \\
AR & 81 \\
AZ & 362 \\
CA & 2254 \\
CO & 842 \\
CT & 2495 \\
DC & 284 \\
DE & 182 \\
FL & 1423 \\
GA & 1222 \\
HI & 17 \\
IA & 188 \\
ID & 64 \\
IL & 2662 \\
IN & 1264 \\
KS & 136 \\
KY & 253 \\
LA & 2064 \\
MA & 4090 \\
MD & 1317 \\
ME & 57 \\
MI & 4049 \\
MN & 428 \\
MO & 358 \\
MS & 310 \\
MT & 16 \\
NC & 430 \\
ND & 25 \\
NE & 78 \\
NH & 86 \\
NJ & 7910 \\
NM & 151 \\
NV & 262 \\
NY & 19415 \\
OH & 1056 \\
OK & 238 \\
OR & 109 \\
PA & 2458 \\
& \\
\end{tabular}


RI 341

SC $\quad 275$

SD 21

TN 219

TX 884

UT 50

VA 684

VT 52

WA 834

WI 340

WV 50

WY 7 
Table 2. The number of COVID-19 deaths reported by each U.S. state and the District of Columbia as of May 5, 2020, according to the COVID Tracking Project's spreadsheet.

By contrast, the total number of deaths predicted by the IHME to happen in the United States by July 30 , 2020 was 81,111 . This means that, nationally, $62,698 / 81,111=$ about $77.3 \%$ of the cumulative number of COVID-19 deaths in the United States predicted to happen by July 30, 2020 had already happened by May $5,2020$.

Of the 50 states and the District of Columbia $(\mathrm{n}=51), 8$ of them (7 states-Maryland, Massachusetts, 
Connecticut, Illinois, New Jersey, New York, and Rhode Island-and the District of Columbia) had already surpassed the best-estimate prediction of the cumulative number of deaths. Clearly, given that they had surpassed these predictions by May 5 even though the predicted numbers were not supposed to be reached until July 30, the prediction was significantly too low in these regions. In other words, $8 / 51=$ about $15.7 \%$ of the included regions had surpassed the cumulative predicted number of deaths almost three months earlier than expected. Of these 8 regions, 2 of them $(25 \%$ of the states that had already surpassed the predicted number of deaths, and $2 / 51=3.9 \%$ of the total) had surpassed even the IHME's upper bound. In total, of the 51 included regions in the current study, 24 of them $(24 / 51=47.1 \%)$ had surpassed the IHME's lower bound. These 24 included the aforementioned 8 regions that had surpassed the IHME's best-estimate prediction, as well as 16 that had not. The remaining 27 regions (all states) had not yet surpassed even the IHME's lower bound. Figure 1, below, illustrates this pattern of results in a map.

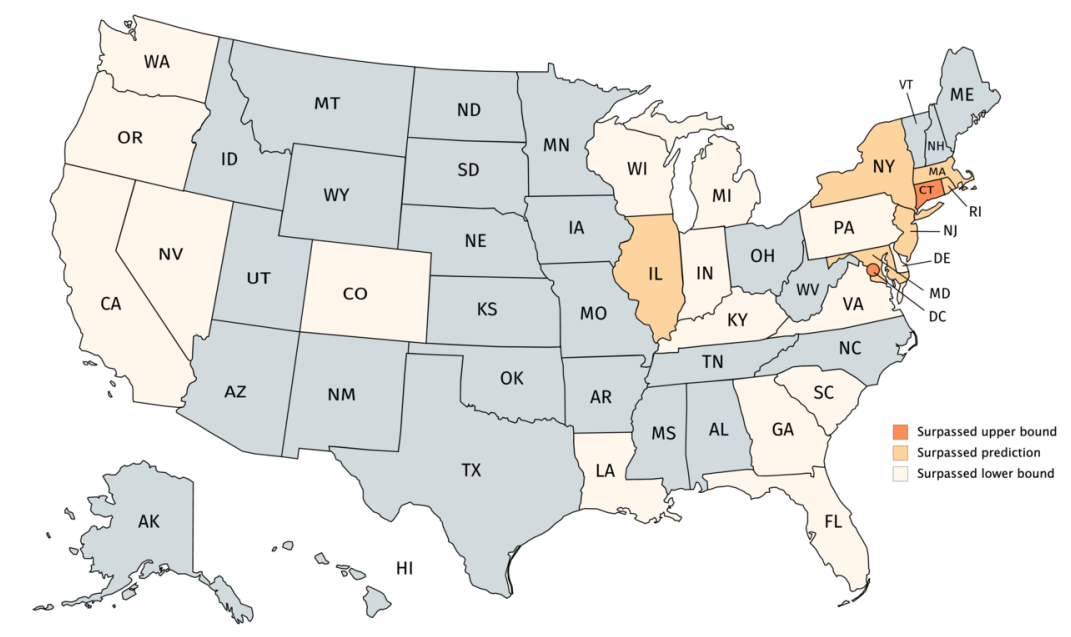

Figure 1: The 50 U.S. states and District of Columbia colored to reflect whether they had surpassed any of the IHME report's three predicted numbers of cumulative COVID-19 deaths. States that had surpassed only the lower bound are shown the lightest shade of red (almost white, e.g. Florida), those that had surpassed both the lower bound and the best estimate are shown a somewhat darker shade (e.g. Illinois), and the two regions that had surpassed all three of the IHME's values (lower bound, best-estimate prediction, and upper bound) are shown in the darkest shade of red (those two being Connecticut and the District of Columbia).

Finally, consulting the COVID Tracking Project's historical data for the United States reveals that on the date the IHME's paper was published (March 30, 2020), the total number of COVID-19 deaths reported in the United States was 3,060, including 1 death from Guam and 6 from Puerto Rico. When we only include deaths from the 50 US states and DC, the number for March 30 thus drops to 3,053; as noted earlier, by May 5,2020 , that number had grown to 62,698 . This increase of $62,698-3,053=59,645$ deaths occurred over 36 days, reflecting about $59,645 / 36=1,657$ new deaths per day on average during that time period. In the 86 days between May 5 and July 30, 2020 (the date to which these predictions apply), assuming a constant rate of growth in deaths, the number of total deaths accumulated will be $86^{*} 1,657=142,485$, for a total of $62,698+142,485=205,813$ deaths in the United States. By contrast, in order to have exactly the predicted number of deaths in the United States on July 30, we would need to accumulate exactly 81,111-62,698=18,413 
additional deaths in the 86-day period between May 5 and July 30. This would require reducing new deaths per day nationally to an average of about 214 -only about $12.9 \%$ of the average number for the 36 days between March 30 and May 5. This seems very unlikely given a recent White House report projecting that the number of new deaths per day would continue to increase into June, and would reach about 3,000 by June 1.("Models Project Sharp Rise in Deaths as States Reopen", 2020) Furthermore, extrapolating into the future for each state based on the average number of deaths per day in each state indicates that the 51 regions included here are almost exactly evenly split between those expected to exceed the IHME prediction $(n=26)$ and those expected to fall below it $(n=25)$. The difference between the IHME's best estimates for the number of deaths in each state by July 30 to the number predicted based on the linear trend just described is illustrated in the table below.

\begin{tabular}{|c|c|c|}
\hline State & Predicted cumulative deaths & Predicted based on trend since $3 / 30(7 / 30)$ \\
\hline New York & 10,243 & 62,886 \\
\hline New Jersey & 4,109 & 26,333 \\
\hline Massachusetts & 2,231 & 13,564 \\
\hline Michigan & 4,061 & 13,282 \\
\hline Illinois & 2,454 & 8,847 \\
\hline Connecticut & 773 & 8,369 \\
\hline Pennsylvania & 3,094 & 8,213 \\
\hline California & 6,109 & 7,321 \\
\hline Louisiana & 2,081 & 6,553 \\
\hline Florida & 3,342 & 4,672 \\
\hline Maryland & 857 & 4,427 \\
\hline Indiana & 2,440 & 4,200 \\
\hline Georgia & 3,165 & 3,933 \\
\hline Ohio & 2,733 & 3,486 \\
\hline Colorado & 940 & 2,732 \\
\hline Virginia & 1,543 & 2,258 \\
\hline Washington & 1,429 & 2,234 \\
\hline Minnesota & 1,280 & 1,427 \\
\hline Rhode Island & 245 & 1,146 \\
\hline Wisconsin & 853 & 1,119 \\
\hline Mississippi & 675 & 1,012 \\
\hline District of Columbia & 132 & 941 \\
\hline South Carolina & 768 & 889 \\
\hline Nevada & 801 & 852 \\
\hline Kentucky & 585 & 836 \\
\hline Delaware & 228 & 602 \\
\hline Texas & 5,847 & 2,915 \\
\hline North Carolina & 2,411 & 1,443 \\
\hline Missouri & 2,977 & 1,182 \\
\hline Arizona & 1,687 & 1,179 \\
\hline Alabama & 1,155 & 989 \\
\hline Oklahoma & 898 & 766 \\
\hline Tennessee & 1,551 & 711 \\
\hline Iowa & 742 & 623 \\
\hline New Mexico & 513 & 507 \\
\hline Kansas & 669 & 442 \\
\hline Oregon & 584 & 331 \\
\hline New Hampshire & 318 & 284 \\
\hline Nebraska & 437 & 260 \\
\hline
\end{tabular}




$\begin{array}{lll}\text { Arkansas } & 707 & 258 \\ \text { Idaho } & 388 & 203 \\ \text { Maine } & 334 & 186 \\ \text { West Virginia } & 460 & 167 \\ \text { Utah } & 619 & 160 \\ \text { Vermont } & 386 & 148 \\ \text { North Dakota } & 163 & 80 \\ \text { South Dakota } & 201 & 69 \\ \text { Hawaii } & 352 & 58 \\ \text { Montana } & 251 & 45 \\ \text { Wyoming } & 136 & 24 \\ \text { Alaska } & 154 & 23\end{array}$

$2600.0 \%$

$2500.0 \%$ 


\begin{tabular}{lll}
\hline State & Predicted cumulative deaths & Predicted based on trend since $3 / 30(7 / 30)$ \\
New York & 10,243 & 62,886 \\
New Jersey & 4,109 & 26,333 \\
Massachusetts & 2,231 & 13,564 \\
Michigan & 4,061 & 13,282 \\
Illinois & 2,454 & 8,847
\end{tabular}




\begin{tabular}{|c|c|c|}
\hline Connecticut & 773 & 8,369 \\
\hline Pennsylvania & 3,094 & 8,213 \\
\hline California & 6,109 & 7,321 \\
\hline Louisiana & 2,081 & 6,553 \\
\hline Florida & 3,342 & 4,672 \\
\hline Maryland & 857 & 4,427 \\
\hline Indiana & 2,440 & 4,200 \\
\hline Georgia & 3,165 & 3,933 \\
\hline Ohio & 2,733 & 3,486 \\
\hline Colorado & 940 & 2,732 \\
\hline Virginia & 1,543 & 2,258 \\
\hline Washington & 1,429 & 2,234 \\
\hline Minnesota & 1,280 & 1,427 \\
\hline Rhode Island & 245 & 1,146 \\
\hline Wisconsin & 853 & 1,119 \\
\hline Mississippi & 675 & 1,012 \\
\hline District of Columbia & 132 & 941 \\
\hline South Carolina & 768 & 889 \\
\hline Nevada & 801 & 852 \\
\hline Kentucky & 585 & 836 \\
\hline Delaware & 228 & 602 \\
\hline Texas & 5,847 & 2,915 \\
\hline North Carolina & 2,411 & 1,443 \\
\hline Missouri & 2,977 & 1,182 \\
\hline Arizona & 1,687 & 1,179 \\
\hline Alabama & 1,155 & 989 \\
\hline Oklahoma & 898 & 766 \\
\hline Tennessee & 1,551 & 711 \\
\hline Iowa & 742 & 623 \\
\hline New Mexico & 513 & 507 \\
\hline Kansas & 669 & 442 \\
\hline Oregon & 584 & 331 \\
\hline New Hampshire & 318 & 284 \\
\hline Nebraska & 437 & 260 \\
\hline Arkansas & 707 & 258 \\
\hline Idaho & 388 & 203 \\
\hline Maine & 334 & 186 \\
\hline West Virginia & 460 & 167 \\
\hline Utah & 619 & 160 \\
\hline Vermont & 386 & 148 \\
\hline North Dakota & 163 & 80 \\
\hline South Dakota & 201 & 69 \\
\hline Hawaii & 352 & 58 \\
\hline Montana & 251 & 45 \\
\hline Wyoming & 136 & 24 \\
\hline Alaska & 154 & 23 \\
\hline
\end{tabular}




\section{Discussion}

This study compared the predicted number of deaths in each US state as of May 5, 2020 to the number predicted on March 30, 2020 for four months later (July 30, 2020). The findings show that, as expected, in most states the actual number of deaths on May 5 was lower than the predicted number for July 30 (almost three months later). Nationally, there were about $77 \%$ as many deaths in the United States on May 5 as the IHME predicted there would be on July 30 .

However, the accuracy of the predictions was highly variable across states, and of the 51 regions (50 states and the District of Columbia) included here, 8 of them had already surpassed the predicted number of deaths nearly three months in advance. Furthermore, extrapolating the number of new deaths per day in the 36 days between the IHME's publication of their article to the writing of the present paper until July 30 leads to the prediction of 213,689 deaths in the United States by that date, more than double the IHME's prediction of 81,111 deaths. Hence, these results corroborate other arguments that the IHME's predictions for the United States are overly optimistic.(Piper, 2020)(Cancryn, 2020)

\section{References}

Where The Latest COVID-19 Models Think We're Headed - And Why They Disagree. (2020). FiveThirtyEight. https://projects.fivethirtyeight.com/covid-forecasts/

Forecasting COVID-19 impact on hospital bed-days ICU-days, ventilator-days and deaths by US state in the next 4 months. (2020). MedRxiv. https://doi.org/10.1101/2020.03.27.20043752 
https://docs.google.com/spreadsheets/u/2/d/e/2PACX-1vRwAqp96T9sYYq2-

i7Tj0pvTf6XVHjDSMIKBdZHXiCGGdNCOypEU9NbngS8mxea55JuCFuua1MUe0j5/pubhtml .

https://docs.google.com/spreadsheets/u/2/d/e/2PACX-1vRwAqp96T9sYYq2-

i7Tj0pvTf6XVHjDSMIKBdZHXiCGGdNCOypEU9NbngS8mxea55JuCFuua1MUe0j5/pubhtml

(2020). The New York Times. https://www.nytimes.com/2020/05/04/us/coronavirus-live-updates . html

This coronavirus model keeps being wrong. Why are we still listening to it?. (2020). Vox. https://www. vox.com/future-perfect/2020/5/2/21241261/coronavirus-modeling-us-deaths-ihme-pandemic

How overly optimistic modeling distorted Trump team's coronavirus response. (2020). Politico. https: //www.politico.com/news/2020/04/24/trump-coronavirus-model-207582 